\title{
Evaluation of Air Quality in the City of Villavicencio based on the Monitoring of Particulate Matter (PM 2.5 and PM 10) with Respect to Current Regulations
}

\author{
${ }^{1}$ Lauren Isaza, ${ }^{2}$ Eduardo Marquez and ${ }^{3}$ Javier Vargas \\ ${ }^{1}$ Department of Basic Sciences and Engineering, University of Corporation-UNIMINUTO, \\ Cra36 Villavicencio, Colombia \\ ${ }^{2}$ Department of Environment, CEPES University, Salazar Nte 26, Col. Cuauhtemoc, Mexico \\ ${ }^{3}$ Department of Educational Sciences, Faculty of Engineering, \\ Cooperative University of Colombia, Km 1 Via Pto. Lopez, Villavicencio, Colombia \\ lisazadomin@uniminuto.edu.co,+573214890184
}

\begin{abstract}
The study presents the analysis of air quality presented in the city of Villavicencio in the Department of Meta in Colombia. Being a city with a dynamic growth the air pollution is more evident every day. Therefore, a correlational study was carried out between the particulate matter and the physical environmental variables. It also presents a diagnosis of the perception of air quality by the population under study. This analysis allowed to find the mathematical models and their respective dependence based on linear correlation. It was determined that the behavior of the Particulate Matter (PM 2.5 and PM 10) within the study zone is in the limits with respect to national and international regulations.
\end{abstract}

Key words: Air quality, environmental assessment, particulate matter, meteorological variables, perception, correlational

\section{INTRODUCTION}

Air quality is a very important today issue, taking into account the levels of air pollution that has been generated in the different countries of the world why different nations have been alerted to monitor and necessary controls regarding atmospheric pollutants (particulate matter, chemicals, etc.), in order to take preventive action and thus, reduce the negative environmental impact that has occurred on planet Earth (Hernandez, 2015).

In 1949 the scientific committee of the Soviet Union presents a study about the harmful effects of air pollution on people and it becomes necessary to set a permissive limits atmospheric concentration present in indoor and outdoor areas. It is also important to consider people of different cities, provided greater protection for children and the elderly as they are more vulnerable to diseases caused by the harmful effects of pollutants circulating through the air. The data obtained from the study of Soviet scientists investigating these side effects reflected in the health of people like; sneezing, coughing and shortness of breath, suck result of small concentrations of impurities found in the atmosphere. Over the years and in the 21 century, the issue of quality air is of interest to the academic and scientific community which is supported by the UN (United Nations) and UNESCO through different protocols and connections of different countries towards mitigate environmental pollution which has caused; the greenhouse effect and global warming, following the high levels of contamination occurring in the atmosphere (Anderson et al., 2016; Trujillo, 2015; Ubilla and Yohsnnessen, 2017).

Figure delivery WHO as infections of the airways in humans are linked to air pollution occurs at present, these diseases are associated by the use of fuel in homes, passive to snuff exposure or cigarette and on the outside of the air quality in developing countries $42 \%$ is attributed to environmental causes while in developed countries becomes $20 \%$.

Background: Since, 1997 in the capital of Colombia, Bogota has installed monitoring stations for monitoring air quality, taking into account the economic and population growth of the city, there has been deterioration of air in this city capital which is measured in real time according to the physical and weather conditions of the city, this monitoring network is to establish what the current trends of pollutants in the city are in order to generate public policies in the locality

Corresponding Author: Lauren Isaza, Department of Basic Sciences and Engineering, University of Corporation-UNIMINUTO, Cra36 Villavicencio, Colombia, lisazadomin@uniminuto.edu.co, +57 3214890184 
and develop relevant strategies to improve the environmental conditions of Bogota and its inhabitants (Fernandez-Nino et al., 2018; Davila et al., 2019).

In the city of Medellin and other municipalities in the Department of Antioquia in Colombia, develop industrial activities and transport, releasing pollutants into the atmosphere whose habitat is a bit airy and narrow which negatively affects the quality of the air people they inhabit this area. In the analysis of these particles showed that concentrations of TSP (Total Suspended Particulates) and PM 10 exceed the standards by the WHO whose tendency is not favorable as it increases the flow of traffic, it can also be observe the presence of other contaminants at low concentrations, it can be concluded that air pollution presented in the Department of Antioquia is high which has generated negative consequences on the health of citizens, affecting, especially, children and the elderly (Fernandez-Nino et al., 2018).

In recent times the population has been affected by industrial development between the twentieth and twenty-first century, so, it is very important to conduct research regarding the different forms of risk communication to the public and its consequences facing the problem of pollution atmosphere that exists today (Liu et al., 2016). Aware of this problem in Latin America increased research into air quality in two intermediate cities in Chile interviews were conducted, analyzing the information through software in order to implement a strategy in the process of visibility and understanding of risk versus these contaminants (Vallejos-Romero and Onate, 2013; Jaitman, 2015).

The Ministry of Environment of Peru, between 2013 and 2014, generated a national report regarding air quality, the report shows that in the city of Cusco, Pasco, Chiclayo, Pisco and Chachapoyas a growing trend presents PM 10 and 2.5 particulate material while in lower concentrations Chimbote and Juliaca according indicating regulations in Peru and $\mathrm{WHO}$ is presented (Vazquez-Rowe et al., 2018).

In Mexico city, they have a monitoring system to measure the following pollutants; $\mathrm{SO}_{2}, \mathrm{CO}, \mathrm{NOX}, \mathrm{O}_{3}$, suspended particles in different parts of the city which are governed according to the Mexican official standard (NOM-021-SSA1-1993) where a limit for the concentration of these contaminants is established in ambient air at a set time (Garza, 1996).

The research presented in this study I address an environmental problem worldwide which multiple impairments and depletion of natural resources by the problem of pollution that occurs in different sectors of the planet is evident every day. Likewise, the UN, UNESCO in its research studies and data analysis make the recommendation that all countries in the world such studies to keep a real-time control of pollutants that occur on the planet generated land.

\section{MATERIALS AND METHODS}

The type of research carried out is projective because it aims to design a proposal to resolve certain situation. This proposal is aimed at measuring the quality of air in the city of Villavicencio, taking into account the meteorological variables of the city, techniques and measuring instruments according to the protocol of surveillance and monitoring in Colombia they will be used in order to the evaluation of air quality and propose a strategic plan that will help to improve this process in the city (Table 1 ).

The research was divided into two parts, one is the measurement of particulate matter and the other party under the perception survey of air quality the inhabitants of Villavicencio.

Measurement phases of PM 10, PM 2.5 and meteorological variables indicators: The study was conducted in four phases. Phase 1 Identification of industrial zones. Stage 2, measurement of particulate matter and weather variables. Phase 3, processing techniques and data analysis. Finally, the last phase assessment of air quality was named according to current regulations. Implementation phases survey the population of the city of Villavicencio.

Table 1: Operationalization of variables

\begin{tabular}{|c|c|c|c|}
\hline Variables & Dimensions & Indicators & Instruments \\
\hline \multirow[t]{3}{*}{$\begin{array}{l}\text { Air quality in the } \\
\text { city of Villavicencio }\end{array}$} & Particulate material & $\begin{array}{l}\text { PM } 2.5 \text { measurement } \\
\text { Measurement of PM } 10 \\
\text { Compared to the protocol of air quality } \\
\text { Legal regulations }\end{array}$ & Aerosol monitor protocol \\
\hline & Meteorological factors & $\begin{array}{l}\text { Measurement of wind direction } \\
\text { Measurement of solar radiation } \\
\text { Measuring temperature and humidity }\end{array}$ & $\begin{array}{l}\text { Anemometer } \\
\text { Pyranometer } \\
\text { Dry bulb thermometer }\end{array}$ \\
\hline & $\begin{array}{l}\text { Social factors and cognitive } \\
\text { assessment of air quality }\end{array}$ & $\begin{array}{l}\text { Perceived level of air quality } \\
\text { Sources of environmental pollution } \\
\text { Knowledge of environmental pollution }\end{array}$ & Survey (questionnaire) \\
\hline
\end{tabular}


Table 2: Techniques and tools for data collection

\begin{tabular}{ll}
\hline Techniques & Instruments \\
\hline Population survey of the downtown area of the city of Villavicencio & Questionnaire in order to evaluate the perception of air quality \\
Method active absorption (low or high volume sensor) & Aerometer; DustTrak Monitor Model DRX 8533 \\
Diffuse irradiance & Pyranometer; solar radiation \\
Direct method (digital form) & Thermometer thermal stress \\
\hline
\end{tabular}

The survey application developed in four phases: Phase 1 survey design was designated. Phase 2 instrument validation and implementation of the survey. Phase 3, processing techniques and data analysis. Finally, the last stage diagnosis and perceived air quality was called.

Population and sample: Villavicencio is a city that has approximately a population of more than 900,000 inhabitants and an area of $1328 \mathrm{~km}^{2}$, located at $4^{\circ} 09^{\prime} 12^{\prime \prime}$ North Latitude and $73^{\circ} 38^{\prime} 06^{\prime \prime}$ West Longitude at an altitude of $467 \mathrm{~m}$ above sea level, the city limits the North with the municipalities of Calvary and Restrepo, South to San Carlos de Guaroa and Acacias, the East with Puerto Lopez and the West with Acacias and Cundinamarca. The target population will be focused on three essential points which are the main thoroughfares of the city, via. Puerto Lopez; via. Restrepo and via. Bogota.

The city of Villavicencio in recent years has grown exponentially and can be compared with five metropolitan areas in Mexico which the transportation institute assessed the negative impact of congestion public transport, local pollution and greenhouse gases. (Perez-Cirera et al., 2018). Also, in China in 2013 according to statistics from the Ministry of Housing and Urban Development, the urbanization rate was $53.73 \%$ and is expected that by 2033 this figure will grow and stabilize at $65 \%$, the urbanization and development improving health conditions and services for humans but has led to problems of air pollution not only in this region but globally (Luo et al., 2015). Villavicencio comparing with the cities of Mexico and China, discussed above, supports the need to undertake research in order to study air quality.

Therefore, the sample I was composed of the following external points, via. Puerto Lopez (Latitude $4^{\circ} 06^{\prime} 59^{\prime \prime} \mathrm{N}$, Longitude $73^{\circ} 36^{\prime} 38^{\prime \prime} \mathrm{O}$ ), via. Bogota (Latitude: $4^{\circ} 18.07$ and $73^{\circ} 51.58 \mathrm{~W}$ ) and via. Restrepo (Latitude $4^{\circ} 07^{\prime} 31 \mathrm{~N}$, Longitude: $73^{\circ} 3821.18$. O) which are located within the perimeter of the city of Villavicencio the following map shows the points.

Techniques and instruments of research: The techniques used for data collection were the survey, active absorption method, diffuse irradiance and direct method, this is presented in Table 2 .
Tabla 3: Average data collected

\begin{tabular}{ll}
\hline Parameters & Values \\
\hline Hour & $9: 20: 20$ \\
PM 2.5 & 0.0204 \\
PM 10 & 0.03008 \\
TA & 28.11 \\
HR & 77.0 \\
RS & 138.6 \\
\hline
\end{tabular}

Tabla 4: TA formulas found, HR and RS

\begin{tabular}{ll}
\hline Parameters & Formulas \\
\hline TA & $\mathrm{y}=-777.6 \mathrm{x}^{2}+681084 \mathrm{x}-120.14$ \\
HR & $\mathrm{y}=14126 \mathrm{x}^{2} .11781 \mathrm{x}+2517.1$ \\
RS & $\mathrm{y}=-285120 \mathrm{x}^{2}+240696 \mathrm{x}-49906$ \\
\hline
\end{tabular}

\section{RESULTS AND DISCUSSION}

The results obtained from measurements of PM 10 and PM 2.5 variables, solar radiation, humidity and temperature are shown in the following analyzes.

Analysis of data collected particulate matter PM 2.5, PM 10 and meteorological variables: Table 3 shows the average of data collected particulate matter and the following weather variables; Solar Radiation (RS), Temperature (RT) and Humidity (RH). Table 4 shows the formulas found meteorological variable; Solar Radiation (RS), Temperature (RT) and Humidity (RH). Figure 1 presents equations of meteorological variables; Solar Radiation (RS), Temperature (RT) and Humidity (RH). Table 5 shows the correlation between particulate (PM 10 and PM 2.5) and weather variables; Solar Radiation (RS), Temperature (RT) and Humidity (RH).

Therefore, the data collected with an analysis of linear correlation between the particulate matter PM 2.5 and weather variables was performed; Room Temperature (RT), Solar Radiation (RS) and Relative Humidity (RH). Table 6 shows correlations between PM 2.50 .8166 vs. TA, of between -0824 and PM 2.5 vs. HR 0822 between PM 2.5 vs. RS. As for the correlations between PM 10 vs. TA is 0.835 , of between - 0855 vs. HR PM 10 and PM 10 and 0.813 between RS. Therefore, the obtained linear correlation analysis for each correlation linear regression. The model obtained for PM 2.5 and TA variables shown in the following Eq. 1:

$$
y=-777.6 x^{2}+681.84 x-120.14
$$


Tabla 5: Correlation between particulate matter and meteorological variables

\begin{tabular}{lllcc}
\hline Variables & PM 2.5 & PM 10 & TA & HR \\
\hline PM 2.5 & 1 & & & \\
PM 10 & 0.8519 & 1 & 1 & \\
TA & 0.8166269 & 0.835643 & -0.996559 & 1 \\
HR & -0.82499 & -0.85589 & 0.9987896 & -0.99943 \\
RS & 0.8222689 & 0.813423 & 1 \\
\hline
\end{tabular}

Table 6: Correlation between variables

\begin{tabular}{lr}
\hline Variables & Correlations \\
\hline PM 2.5 vs. TA & 0.8166269 \\
PM 2.5 vs. HR & -0.8249900 \\
PM 2.5 vs. RS & 0.8222689 \\
PM 10 vs. TA & 0.8356430 \\
PM 10 vs. HR & -0.8558900 \\
PM 10 vs. RS & 0.8134230 \\
\hline
\end{tabular}

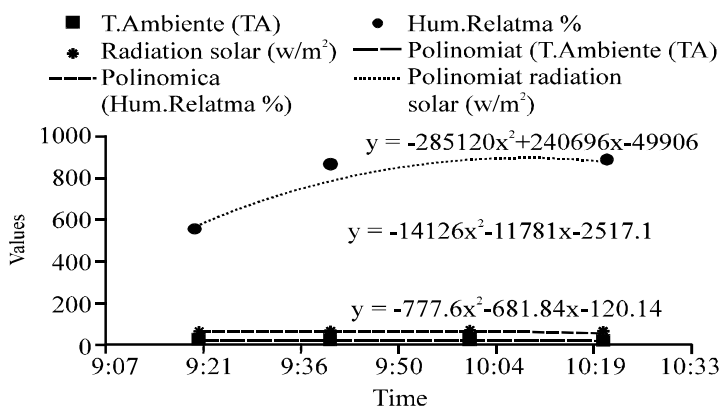

Fig. 1: Equations of variables; TA, HR and RS

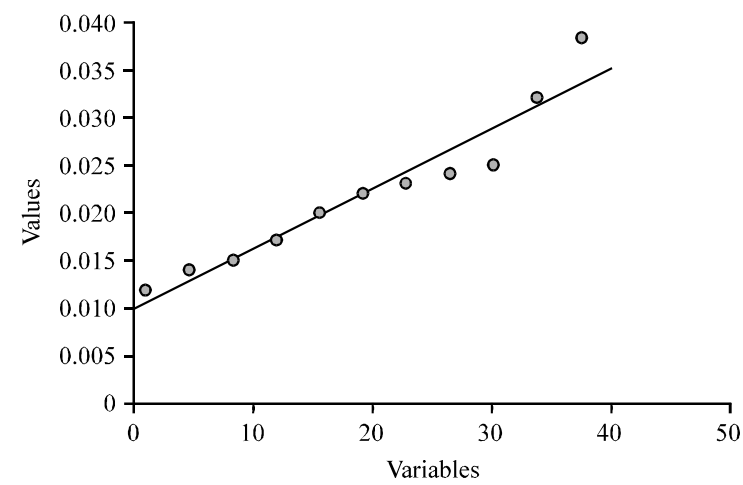

Fig. 2: Particulate material behavior between PM 2.5 and temperature

In Fig. 2, data distribution and trend line of the calculated regression is presented which it is evident that by increasing the ambient temperature rises particulate matter PM 2.5. The model obtained for PM 2.5 and TA variables shown in the following Eq. 2 :

$$
y=14126 x^{2}-11781 x+2517.1
$$

In Fig. 3, it shows that there is an inverse relationship between HR and PM 2.5 indicator, demonstrating that

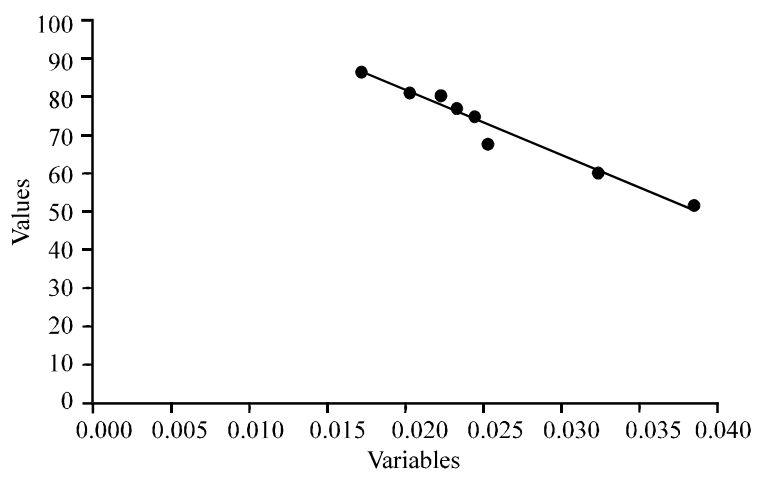

Fig. 3: Particulate material behavior between PM 2.5 and relative humidity

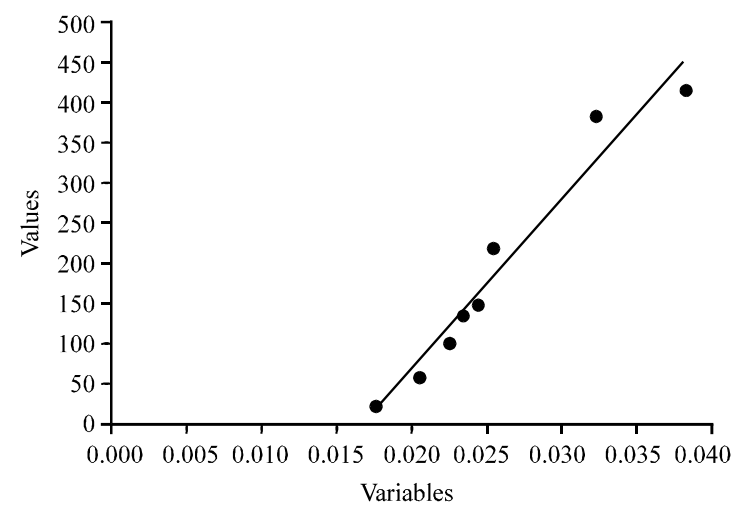

Fig. 4: Particulate material behavior between PM 2.5 and solar radiation

increasing the relative humidity decreases particulate matter PM 2.5. The model obtained for PM 2.5 and TA variables shown in the following equation:

$$
y=-285120 x^{2}+240696 x-49906
$$

In Fig. 4, it shows that there is a direct relationship between the RS and PM 2.5 indicator, demonstrating that increasing solar radiation increases the particulate matter PM 2.5. Thus, obtained the linear correlation between PM 10 and PM 2.5 particulate material, the corresponding analysis was performed to give the following model:

$$
y=-13525 x^{3}+721.85 x^{2}-9.471 x+0.0414
$$




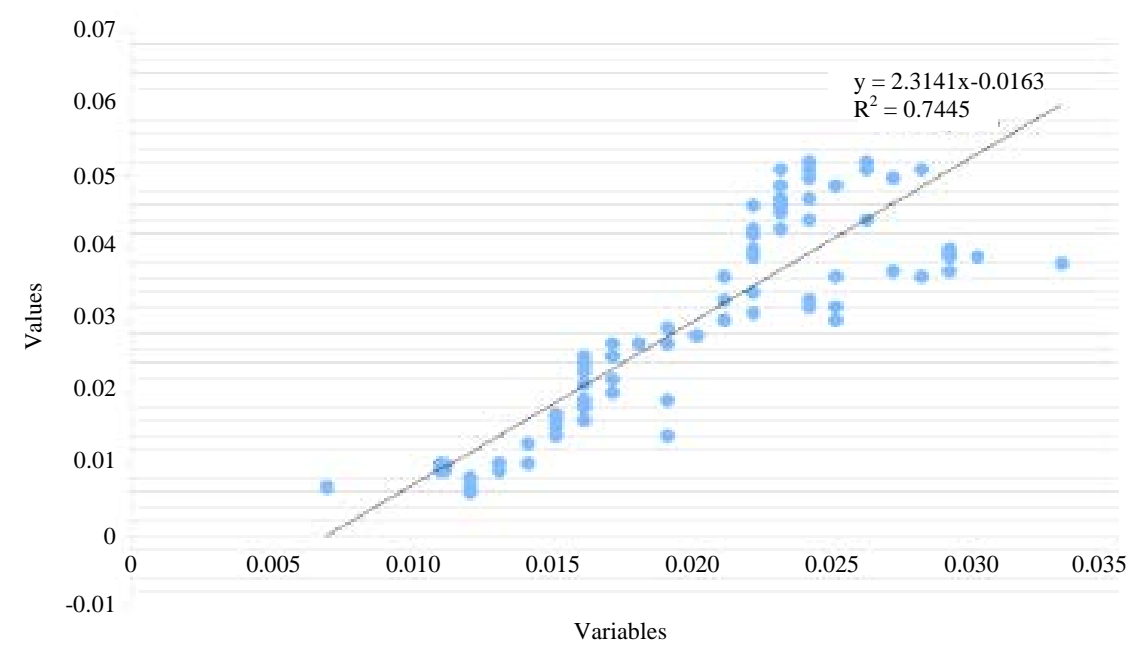

Fig. 5: No linear correlation between PM 2.5 and 10 particulate material

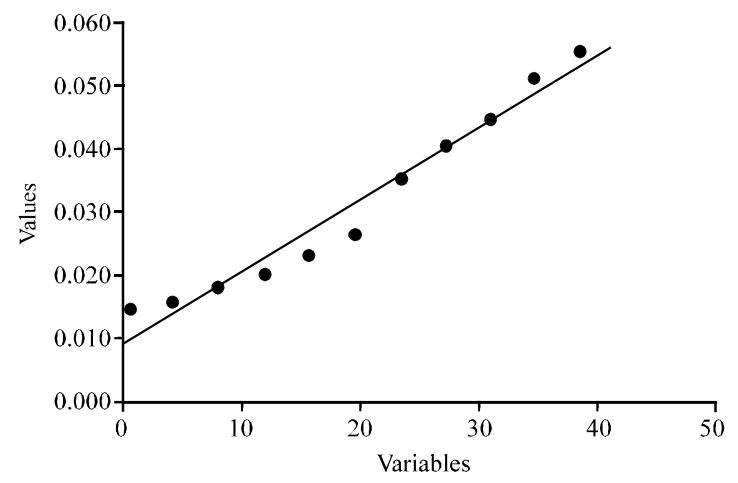

Fig. 6: Particulate material behavior between PM10 and temperature

In Fig. 5, the distribution of data and trend line of the calculated regression which the nonlinear correlation between evidence particulate PM 10 and PM 2.5 presented. In Fig. 6, the distribution of data and trend line of the calculated regression which it is evident that by increasing the ambient temperature rises the particulate PM 10 is presented.

In Fig. 7, it shows that there is an inverse relationship between PM 10 and HR indicator, demonstrating that increasing the relative humidity decreases the particulate PM 10. In Fig. 8, it shows that there is a correlation between PM 10 and RS indicator, demonstrating that increasing solar radiation increases the (Particulate Matter) PM 10.

Analysis of the perception survey of air quality: The level of air quality in the city of Villavicencio is affected by public transportation, pollution generated in the unpaved

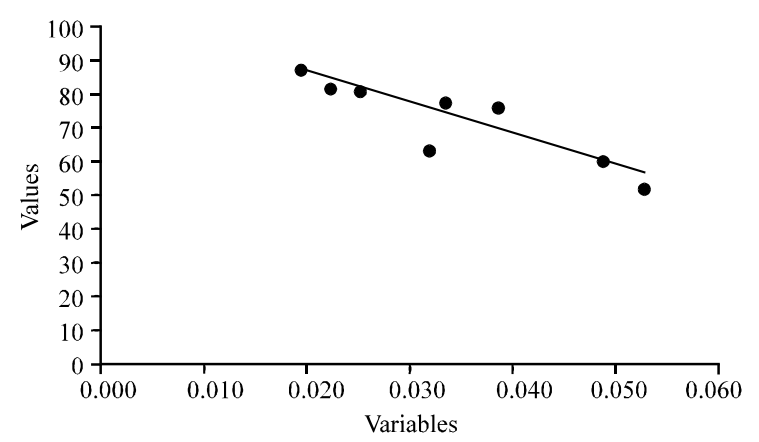

Fig. 7: Particulate material behavior between PM 10 and relative humidity

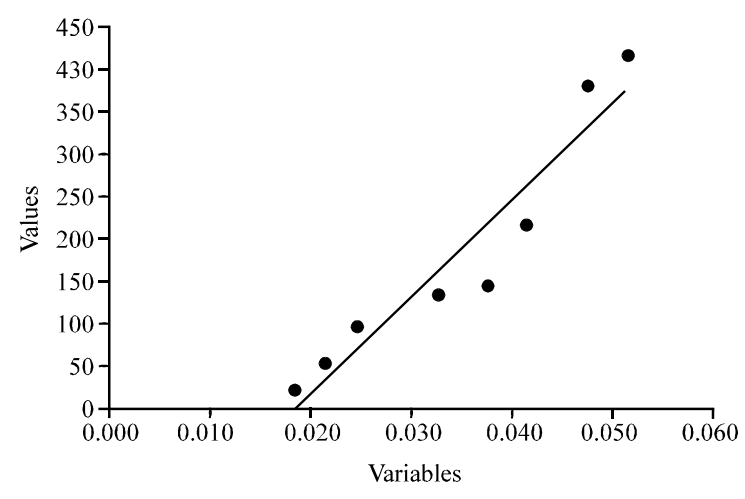

Fig. 8: Particulate material behavior between PM 10 and solar radiation

streets and lack of determining an industrial area in the land use Plan (POT) within the city. Then the results of the survey of perceived air quality applied to the inhabitants of the city of Villavicencio are described. 


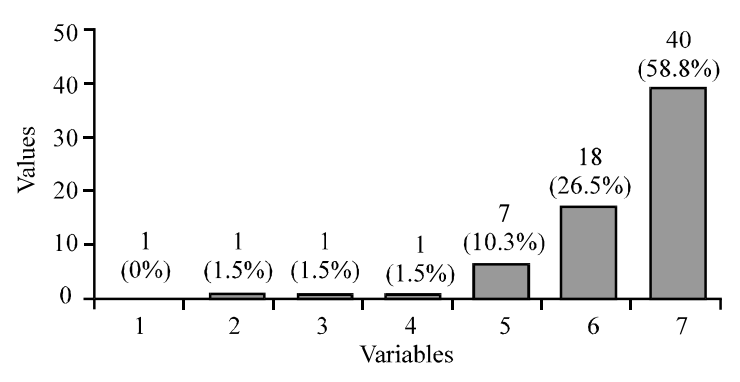

Fig. 9: Public transport

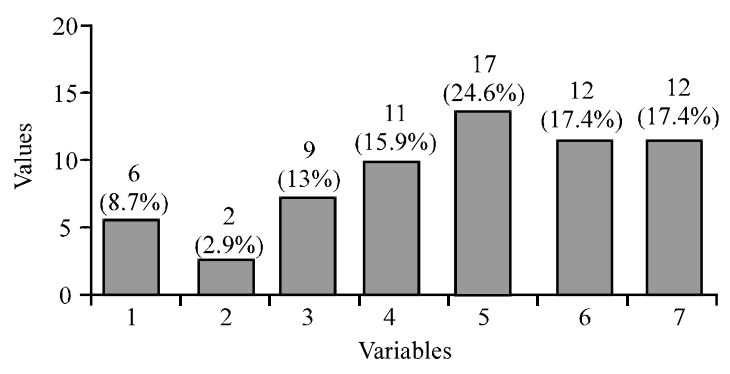

Fig. 10: Meteorological factors in Villavicencio

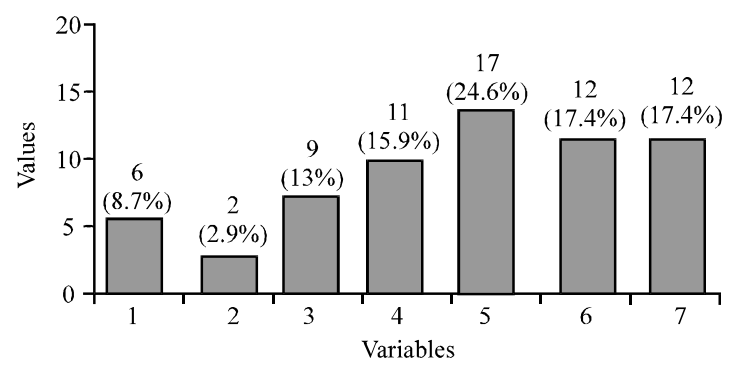

Fig. 11: Pollution in the city

As for the question which if public transport affects the level of air quality in the city of Villavicencio, Fig. 9 shows that $58.8 \%$ corresponding to 225 people consider air quality in the city Villavicencio is greatly affected by public transport while $1.5 \%$ for 6 people believe that air quality in the city of Villavicencio is unaffected by public transport.

Regarding the question, that if meteorological factors affect the level of air quality in the city of Villavicencio, Fig. 10 shows that $24.6 \%$ corresponding to 95 people consider that weather factors affect the level of air quality in the city of Villavicencio while $8.7 \%$ for 33 people consider that weather factors do not affect the level of air quality in the city of Villavicencio.

Referring to the question which if pollution is a source of air pollution within Villavicencio, Fig. 11 shows that $24.6 \%$ corresponding to 94 people consider pollution generated in some streets unpaved city is a latent source

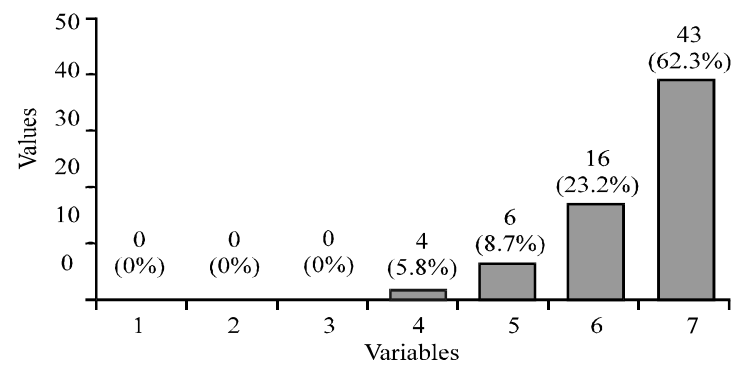

Fig. 12: Air quality in Villavicencio

of environmental pollution while $8.7 \%$ for 34 people consider the pollution that is generated in some city streets unpaved is not a latent source of environmental pollution.

Also, citizens of Villavicencio considered very important to know the air quality of the city daily through relevant media monitoring. Figure 12 presents the $62.3 \%$ for 239 people, if they consider very important to know the air quality in the city of Villavicencio while $5.8 \%$ for 22 people considered not as important to know the air quality in the city of Villavicencio.

According to the survey conducted and considering social factors-cognitive assessment of air quality. It was determined the following: in terms of the perceived level of air quality, $86 \%$ of the study population are clear the importance of the level of air quality which if the air is polluted can affect health negative people, also consider air quality in the city of Villavicencio is being affected by pollution sources such as; mills, public transport, among others whereas the vehicle restriction implemented within a polygon in the city can contribute positively to mitigate air pollution, also manifest congestion and pollution that exists in the city of Villavicencio by vehicular traffic as the city has grown exponentially and this affects the development of it.

Further, in indicator of environmental pollution sources, $84 \%$ of the study population are clear about the sources of environmental pollution are within the city of Villavicencio, considering the following; incinerating tires, the dispersion of hydrocarbons in river sources; rivers or lakes, pollution generated in some areas of the city because they are not paved, welding and metal workshops that are located in residential areas. They also considered important in the land use plan future sources of pollution, marking an as the city has grown and in some cases have been made constructions in wetlands or nature reserves.

Finally, in the aspect of knowledge of environmental pollution, $71 \%$ of the study population, considered very important and of great concern environmental issues not 
Table 7: Presents the results of the PM 10 measurement with respect to the Colombian, Mexican, American and European standards

\begin{tabular}{|c|c|c|c|c|c|c|}
\hline Days & Average PM 2.5 & Protocol 610 in Colombia & Qualification & $\begin{array}{l}\text { Technical standards } \\
\text { NOM-025-SSA1-2014 in Mexico }\end{array}$ & $\begin{array}{l}\text { EPA standard } \\
\text { in the United States }\end{array}$ & European standard \\
\hline 1 & 27.0 & 50 & Buena & 45 & 50 & 25 \\
\hline 2 & 38.1 & 50 & Buena & 45 & 50 & 25 \\
\hline 3 & 51.8 & 50 & Aceptable & 45 & 50 & 25 \\
\hline 4 & 43.1 & 50 & Buena & 45 & 50 & 25 \\
\hline 5 & 30.1 & 50 & Buena & 45 & 50 & 25 \\
\hline 6 & 174.7 & 50 & Danina & 45 & 50 & 25 \\
\hline 7 & 35.4 & 50 & Buena & 45 & 50 & 25 \\
\hline 8 & 50.2 & 50 & Buena & 45 & 50 & 25 \\
\hline 9 & 54.5 & 50 & Aceptable & 45 & 50 & 25 \\
\hline 10 & 46.8 & 50 & Buena & 45 & 50 & 25 \\
\hline
\end{tabular}

Table 8: Evaluation of PM10 particulate matter

\begin{tabular}{|c|c|c|c|c|c|}
\hline Average PM 10 & Protocol 610 in Colombia & Qualification & $\begin{array}{c}\text { Technical standards } \\
\text { NOM-025-SSA1-2014 in Mexico }\end{array}$ & $\begin{array}{l}\text { EPA standard } \\
\text { in the United States }\end{array}$ & European standard \\
\hline 30.1 & 100 & Buena & 75 & 100 & 50 \\
\hline 31.6 & 100 & Buena & 75 & 100 & 50 \\
\hline 45.2 & 100 & Buena & 75 & 100 & 50 \\
\hline 38.2 & 100 & Buena & 75 & 100 & 50 \\
\hline 29.6 & 100 & Buena & 75 & 100 & 50 \\
\hline 130.7 & 100 & Danina & 75 & 100 & 50 \\
\hline 27.9 & 100 & Buena & 75 & 100 & 50 \\
\hline 33.3 & 100 & Buena & 75 & 100 & 50 \\
\hline 38.8 & 100 & Buena & 75 & 100 & 50 \\
\hline 49.2 & 100 & Buena & 75 & 100 & 50 \\
\hline
\end{tabular}

only in the city of Villavicencio but in the whole world, stating the importance of that in Villavicencio fixed monitoring stations which allow visible air quality in the city of Villavicencio and that this information easily and timely access for citizens also consider it important that environmental debates are promoted campaigns are implemented environmental education and awareness, public policies and strategies to positively contribute to the environment and society. It seems relevant not only in Villavicencio but in Colombia, the use of alternative transportation is motivated (Manual or electric bicycles, electric cars or motorcycles) through painstaking campaigns with competitive price in the international market and is governed by current legal regulations in the country.

Air quality assessment: Table 7 and 8 show the summary of the assessment of air quality with respect to the Colombian standard and compared with other international standards.

Table 8 presents the results of the PM 10 measurement with respect to the Colombian, Mexican, American and European standards. With regard to the comparison of the data obtained in Colombia with the European Standard, it should be borne in mind that the European continent has more infrastructure and development which is why the standard is adjusted to the minimum permissible values while in Colombia still conserves a green lung like the Amazon is rich in flora, fauna and water resources which positively influences air quality, therefore, the standard is adjusted to these permissible values in Colombia.
The behavior of the particulate matter PM 2.5 yielded a result of $0.01989 \mathrm{mg} / \mathrm{m}^{3}$, data that was compared with the norm in Colombia which is $0.050 \mathrm{mg} / \mathrm{m}^{3}$ established in protocol 610 of 2010 , complying with the parameters established in the nation.

The behavior of PM 10 particulate material yielded a result of $0.02975 \mathrm{mg} / \mathrm{m}^{3}$ which was compared with the norm in Colombia which is $0.100 \mathrm{mg} / \mathrm{m}^{3}$ established in protocol 610 of 2010 , complying with the parameters established in the nation.

Comparing these results with the EPA (United States Special Protection Agency) standard, air quality is considered satisfactory and pollutants pose little risk to people's health (EPA., 2018).

The technical regulations NOM-025-SSA1-2014 of the United States of Mexico were also revised with respect to the maximum permissible criteria for atmospheric pollutants where the $24-\mathrm{h}$ average is $0.075 \mathrm{mg} / \mathrm{m}^{3}$ for PM 10 and $0.045 \mathrm{mg} / \mathrm{m}^{3}$ for PM 2.5, comparing these criteria with the results obtained in this investigation are within the values established by the Mexican regulations. The behavior of PM 10 and PM 2.5 particulate matter are within the parameters established by the standard while in Chile the increase of PM2 particulate matter is evident 5 and in order to contribute to its reduction, an alternative is natural gas as the main source for industrial zones which allows reducing emissions and cost savings with respect to liquid fuel as well as in a research study carried out in Peru, the increase of PM 10 particulate matter produced by the burning of biomass can be evidenced and it is necessary to establish a monitoring network in order to control and prevent diseases in 
people, another research was finally, carried out in Mexico in order to evaluate the perception of climate change that is currently being experienced which showed that the indigenous population local climate changes, attributed to air pollution, logging, burning garbage among other aspects that influence air pollution.

\section{CONCLUSION}

According to the regulations in Colombia and compared to other international standards, it can be concluded that the results obtained are consistent with the maximum permissible values set forth in the rule, considering that air quality is satisfactory and meets the parameters established within of the standard, therefore, particulate matter PM 2.5 and PM 10 do not affect the health of people living in the city of Villavicencio.

Within the perception survey, the township population perceives the importance of installing monitoring points air quality that will promote real-time measurement of different pollutants that can air of the city and the wellbeing of its inhabitants short or long term.

\section{ACKNOWLEDGEMENT}

This research was conducted in the exercise of doctoral training in sustainability at the University Pan American Center for Higher Education (CEPES) and was monitero economic co-funding project and characterization of air quality in Villavicencio with C117-40-055 code Corporacion Universitaria Minuto de Dios of UNIMINUTO. We also thank the Universidad Cooperativa de Colombia for its support as a counterpart to it and we provide all the collaborative work both technical and scientific.

\section{REFERENCES}

Anderson, T.R., E. Hawkins and P.D. Jones, 2016. $\mathrm{CO}_{2}$, the greenhouse effect and global warming: From the pioneering work of Arrhenius and Callendar to todays earth system models. Endeavour, 40: 178-187.

Davila, J.G., J. Azcarate and L. Kornov, 2019. Strategic environmental assessment for development programs and sustainability transition in the Colombian post-conflict context. Environ. Impact Assess. Rev., 74: $35-42$.
EPA., 2018. Air quality index basics. Environmental Protection Agency, USA.

Fernandez-Nino, J.A., C.I. Astudillo-Garcia, L.A. Rodriguez-Villamizar and V.A. Florez-Garcia, 2018. Association between air pollution and suicide: A time series analysis in four Colombian cities. Environ. Health, 17: 1-8.

Garza, G., 1996. Uncontrolled air pollution in Mexico City. Cities, 13: 315-328.

Hernandez, R.A., 2015. Prevention and control of air pollution in China: A research agenda for science and technology studies. Surv. Perspect. Integrating Environ. Soc., 8: 1-8.

Jaitman, L., 2015. Urban infrastructure in Latin America and the Caribbean: Public policy priorities. Lat. Am. Econ. Rev., 24: 1-57.

Liu, X., H. Zhu, Y. Hu, S. Feng and Y. Chu et al., 2016. Public's health risk awareness on urban air pollution in Chinese megacities: The cases of Shanghai, Wuhan and Nanchang. Intl. J. Environ. Res. Public Health, 13: 1-14.

Luo, H., N. Wang, J. Chen, X. Ye and Y.F. Sun, 2015. Study on the thermal effects and air quality improvement of green roof. Sustainability, 7: 2804-2817.

Perez-Cirera, V., E. Schmelkes, O. Lopez-Corona, F. Carrera and A.P. Garcia-Teruel et al., 2018. [Income and air quality in cities: Does a Kuznets curve exist for transport emissions in the valley of Mexico's metropolitan area (In Spanish)]. Econ. Q., 85: 745-764.

Trujillo, A.C., 2015. Environmental pollution by energies. Intl. J. Environ. Pollut., 1: 79-88.

Ubilla, C. and K. Yohsnnessen, 2017. Contaminacion atmosferica outdoor air pollution respiratory health effects in children. Rev. Med. Clin. Las Condes, 28: 111-118.

Vallejos-Romero, A. and N. Onate, 2013. Communication of ecological risks: The case of two intermediate cities South of Chile. Intl. J. Environ. Pollut., 29: 59-75.

Vazquez-Rowe, I., R. Kahhat, G. Larrea-Gallegos and K. Ziegler, 2018. Peru's road to climate action: Are we on the right path? The role of life cycle methods to improve Peruvian national contributions. Sci. Total Environ., 659: 249-266. 